\title{
Effects of Xanthan Gum on Rheological Properties of Aloe vera-Moringa Leaf Juice Blends
}

\author{
Victor V Matabura* and Leonard MP Rweyemamu \\ Department of Food Science and Technology, University of Dar es Salaam, P. O. Box 35134, Dar \\ es Salaam, Tanzania \\ Corresponding authors'e-mail addresses: victorvicent10@gmail.com (Matabura); \\ stayfit.foods@gmail.com (Rweyemamu) \\ Received 30 Oct 2020, Revised 26 Mar 2021, Accepted 23 Apr 2021, Published May 2021 \\ DOI: https://dx.doi.org/10.4314/tjs.v47i2.14
}

\begin{abstract}
Understanding the impacts of hydrocolloid agents on the rheological properties of nutraceutical beverages like Aloe vera-moringa juice blend is very useful for functional properties and product stability. To this end, the effects of xanthan gum on rheological properties in Aloe vera-moringa leaf juice blends were investigated using a Brookfield rheometer. Aloe vera-moringa leaf juice blends were prepared and then incorporated with xanthan gum at different ratios $(\mathrm{w} / \mathrm{w})$ of $0.2 \%$, $0.4 \%, 0.6 \%, 0.8 \%$, and $1 \%$. The results revealed that the viscosity of Aloe vera-moringa juice blend was strongly affected by the xanthan gum addition. The viscosity profiles depicted a decreasing trend in viscosity when a shear rate increased. The Aloe vera-moringa leaf juice blend changes from a Newtonian fluid to the non-Newtonian fluid as the xanthan gum fraction increases. Moreover, shear stress was observed to increase with increasing in xanthan gum concentrations. For quantitative analysis, both Power-law and Bingham model equations were fitted to experimental data to easily describe the flow behaviour of the Aloe vera-moringa leaf juice blends. The juices added with xanthan gum of $0.4 \%$ to $1 \%$ were found to show a shear-thinning behaviour, since the flow behaviour index, $n<1$. This implies that the apparent viscosity decreases as the shear rate increases.
\end{abstract}

Keywords: Aloe vera juice, Moringa leaf juice, Xanthan gum, Rheological property, Nutraceutical beverage.

\section{Introduction}

Over the past centuries, the roles of foods were for supporting body growth and prevention of deficiencies (Doyon and Labrecque 2008). To date, knowledge of health-promoting foods has increased to the public. This shift has influenced consumer demands for healthy oriented-foods, which can improve their life beyond basic nutritional requirements. Besides, public awareness has prompted new outlooks to the food sector to produce novel food products (Đorđević et al. 2015) with nutraceutical properties. Several studies describe nutraceutical foods as dietary supplements or food ingredients, which provide medical or health benefits, prevention and treatment of diseases (Shahidi 2012, Goncharov et al. 2016, Sauer and Plauth 2017). In this respect, Aloe spp and Moringa oleifera plants become popular as important nutraceutical food products ( Kumar and Debjit 2010, Chhikara et al. 2020, Sahu et al. 2013). The Aloe vera contains several vitamins, minerals, enzymes, amino acids, natural sugars and large amounts of bioactive compounds such as flavonoids, terpenoids, lectins, fatty 
acids with antioxidant, anti-microbial and antiinflammatory activities (Kumar and Debjit 2010, Sahu et al. 2013, Rahman et al. 2015, Hęś et al. 2019). On the other hand, moringa leaves are rich in macronutrients, micronutrients and antioxidant compounds such as proteins, vitamins, minerals, phytochemicals, tocopherols, polyphenols, flavonoids and carotenoids (Fahey 2005, Aja et al. 2014, Vergara-Jimenez et al. 2017, Chhikara et al. 2020). Fahey (2005) reported that moringa leaves contain double the amount of protein compared to that of milk and egg, respectively, seven times more the vitamin $\mathrm{C}$ contents than that of oranges, and four times the amount of vitamin A than in carrots. It also contains thrice the contents of calcium and iron in moringa leaves compared to those in banana and milk, respectively. In general, the presence of these bioactive constituents has positive effects on human health and could enhance prevention of numerous chronic and degenerative diseases such as cancer, heart disease, stroke, blood glucose, gastrointestinal disorders, and age-related functional decadence (Santos et al. 2019). Furthermore, Aloe vera and moringa leaves have emerged as potential ingredients in different food products and nutritional supplements such as juice and beverage (Sunita and Ananya 2013, Biswas et al. 2016, Boniface et al. 2020), jam (Joy and Rani 2013, Rahman et al. 2015), flour (Alphonce et al. 2019), and extruded snacks (Rweyemamu et al. 2015).

Juice from Aloe vera and moringa leaves can be extracted by mashing the fresh leaves in the presence of water and then filtration. During this process, the majority of large pulp particles are discarded as the smaller micro and nano-size particles pass through the filter cloth and tend to undergo sedimentation with time. They can subsequently be separated by clarification to obtain a clear juice. However, these suspended plant particles may contain bioactive compounds, which are crucial for human health. Both Aloe vera and moringa leaves have been documented to contain a large amount of biochemical compounds (Fahey
2005, Sahu et al. 2013, Aja et al. 2014, Rahman et al. 2015, Vergara-Jimenez et al. 2017, Hęś et al. 2019). Hence, the inclusion of the suspended leaf particles into the Aloe veramoringa leaf juice could enhance desirable nutraceutical properties. From the technological point of view, the presence of these smaller plant particles might affect the product stability and rheological properties, which are related to the sedimentation of the suspended particles during storage (Genovese and Lozano 2001, Liang et al. 2006). For this purpose, an insight on how the rheological properties change is very useful for the description of the flow and textural properties of food products, process design, prediction of food stability, quality control, and in product development by relating texture variations and mouth-feel with a change in rheological properties (Beristain et al. 2006, Liang et al. 2006, Falguera and Ibarz 2010). The rheological properties can also help evaluate the product performance, consumer acceptance, processability, predict product's stability and shelf life. In this content, hydrocolloid agents like xanthan gum have been widely used in food and pharmaceutical industries for thickening, suspending, stabilising and gelling, thus control the rheological properties (Somogyi 1996, Genovese and Lozano 2001, Dickinson 2003, Liang et al. 2006, Mirhosseini et al. 2008, De Cássia da Fonseca et al. 2009, Ibrahim et al. 2011). Dickinson (2003) suggested that hydrocolloid agents tend to interact with protein materials in aqueous solutions, thereby inducing stability effects in different ways, such as repulsive interaction that occurs at low amounts of hydrocolloids or attractive interactions at high amounts of hydrocolloids (Genovese and Lozano 2001, Udomsup et al. 2011).

Xanthan gum is an extracellular polysaccharide, which is produced through the fermentation of carbohydrates by Xanthomonas campestris bacterium (Boyd 2005). Xanthan gum is one of the most versatile and excellent hydrocolloid agents for stabilising food 
suspensions (Genovese and Lozano 2001, Liang et al. 2006). In aqueous solutions like juice, xanthan gum swells and increases the hydrodynamic volume, thus raising the viscosity of the product. It can form a gel network structure because of the chain interaction, particularly when the xanthan gum entrains ample water (Genovese and Lozano 2001, Gawai et al. 2017). In the case of systems containing proteins and polysaccharide, electrostatic interactions may occur and form soluble complex depending on the $\mathrm{pH}$ and ionic strength of the solution and the nature of the hydrocolloids. The proteinhydrocolloid interactions at interface can be related to steric stabilisation and rheology control (Dickinson 2003). Numerous studies also reported that xanthan gum is stable over a wide range of temperature, $\mathrm{pH}$, ionic strength, and chemical reactivity (Liang et al. 2006, Udomsup et al. 2011). Beristain et al. (2006) reported that xanthan gum forms weak gels in juice and exhibited the natural mouth-feel of the product. Several studies have reported the applications of xanthan gum in different juices including carrot juice (Liang et al. 2006), apple juice (Genovese and Lozano 2001, Ibrahim et al. 2011), mangosteen juice (Udomsup et al. 2011), in various types of beverages like energy drinks, sports drinks, carbonated beverages and protein-based beverages (Beristain et al. 2006) and orange beverage (Mirhosseini et al. 2008). However, the literature contains limited information on the applications of xanthan gum in Aloe veramoringa leaf juice blend.

Therefore, this work aimed to investigate the impacts of xanthan gum on rheological properties of Aloe vera-moringa leaf juice blend. The use of xanthan gum in this beverage suits well to investigate and may contribute to our understanding of the stabilisation of insoluble plant particles, and thus could improve the nutraceutical properties of the product. Besides, the Power-law and Bingham model equations were used for rheology description of the Aloe vera-moringa leaf juice.

\section{Materials and methods Materials and chemical reagents}

Fresh leaves of Aloe vera var Chinensis (Aloe chinensis spp.) and moringa (Moringa oleifera) leaves were harvested from a botanical garden of the Mlimani Campus University of Dar es Salaam and entrepreneur Stayfit Nutrisupplies Company Ltd of Dar es Salaam, Tanzania. About $3 \mathrm{~kg}$ moringa leaves and $2 \mathrm{~kg}$ Aloe vera leaves were harvested from their respective plants and immediately brought to the Food Science Laboratory at the Department of Food Science and Technology, University of Dar es Salaam where the experimentation was carried out. Citric acid and sodium benzoate were purchased from Sigma-Aldrich (Steinheim, Germany). Xanthan gum $\left(\mathrm{MW}=2 \times 10^{6} \mathrm{Da}\right)$ was bought from a local supplier Lab Equip Co. Ltd of Dar es Salaam.

\section{Juice extraction and formulation}

Fresh Aloe vera leaves were sorted, stripped-off spikes, washed and sliced with a stainless steel knife. In the case of moringa, matured leaves were stripped-off from the sorted branches and washed with tap water. The prepared leaves of Aloe vera and moringa were mixed at different ratios (w/w) and added with distilled water as shown in Table 1. The formulated samples were separately blanched at $100{ }^{\circ} \mathrm{C}$ for $30 \mathrm{~s}$ in a water bath (Boniface et al. 2020) and then cooled to room temperature using tap water. The blanched sample was placed into a blender (Vitamix S50 blender, UK) for mashing at $1600 \mathrm{rpm}$ for $4 \mathrm{~min}$ according to Boniface et al. (2020). The pulps were filtered through a food-grade fruit juice nylon filter cloth (200-460 mesh). To each filtrate sample, anhydrous citric acid $(0.3 \%)$ was added to adjust $\mathrm{pH}$ to about 3.0 to 3.5 (Matabura and Kibazohi 2021) and followed by adding $0.1 \%$ sodium benzoate, the maximum concentration allowed by Food and Drug Administration (FDA) in food and beverage (Katalenić 2013). The juice blend was stirred thoroughly and placed into a 
holding glass container of $1000 \mathrm{~mL}$ for successive addition of xanthan gum.

Table 1: Aloe vera-moringa leaf juice formulation

\begin{tabular}{llll}
\hline $\begin{array}{l}\text { Juice } \\
\text { blends }\end{array}$ & $\begin{array}{l}\text { Moringa } \\
\text { leaf }(\mathrm{g})\end{array}$ & $\begin{array}{l}\text { Aloe } \\
\text { vera } \\
\text { leaf }(\mathrm{g})\end{array}$ & $\begin{array}{l}\text { Distilled } \\
\text { water }(\mathrm{g})\end{array}$ \\
\hline $\mathrm{S}_{1}$ & 100 & 0 & 1150 \\
$\mathrm{~S}_{2}$ & 100 & 125 & 1025 \\
$\mathrm{~S}_{3}$ & 100 & 250 & 900 \\
$\mathrm{~S}_{4}$ & 100 & 375 & 775 \\
$\mathrm{~S}_{5}$ & 100 & 500 & 650 \\
$\mathrm{~S}_{6}$ & 100 & 625 & 525 \\
\hline
\end{tabular}

\section{Xanthan gum application}

For each Aloe vera-moringa leaf juice blend, five replicate samples with $100 \mathrm{~g}$ were prepared for xanthan gum addition. The xanthan gum was at different ratios of $0.2 \%$, $0.4 \%, 0.6 \%, 0.8 \%$ and $1 \%(\mathrm{w} / \mathrm{w})$ according to Gawai et al. (2017). These samples were bottled in $200 \mathrm{~mL}$ transparent glass bottles and covered with stoppers. A control sample with no xanthan gum was also prepared for each aloe vera-moringa leaf juice.

\section{Rheological properties measurement}

Rheological measurements were carried out by using a Brookfield rheometer (Brookfield R/S plus rheometer, UK) at room temperature. Before testing, the packed samples were placed in room temperature overnight to equilibrate. The rheometer device consisting of a measuring chamber and a coaxial cylinder spindle was employed. The geometric dimensions of the measuring chamber were $36 \mathrm{~mm}$ diameter and $70 \mathrm{~mm}$ height, while the spindle had a diameter of 25 $\mathrm{mm}$ and a height of $45 \mathrm{~mm}$ as exemplified in Figure 1. For each juice sample, $12 \mathrm{~mL}$ was poured into a cleaned and dried chamber of the rheometer. The spindle was then immersed in the juice sample by fixing a measuring chamber to the rheometer. The distance between the end of the spindle and the chamber bottom was kept fixed. From the preliminary tests, the rheometer was set to operate in shear rate ranged between 500 and 3500 per sec. The data for shear stress $(\mathrm{Pa})$ and viscosity $(\mathrm{mPa} s)$ of the Aloe vera-moringa leaf juice were recorded within $40 \mathrm{~s}$.

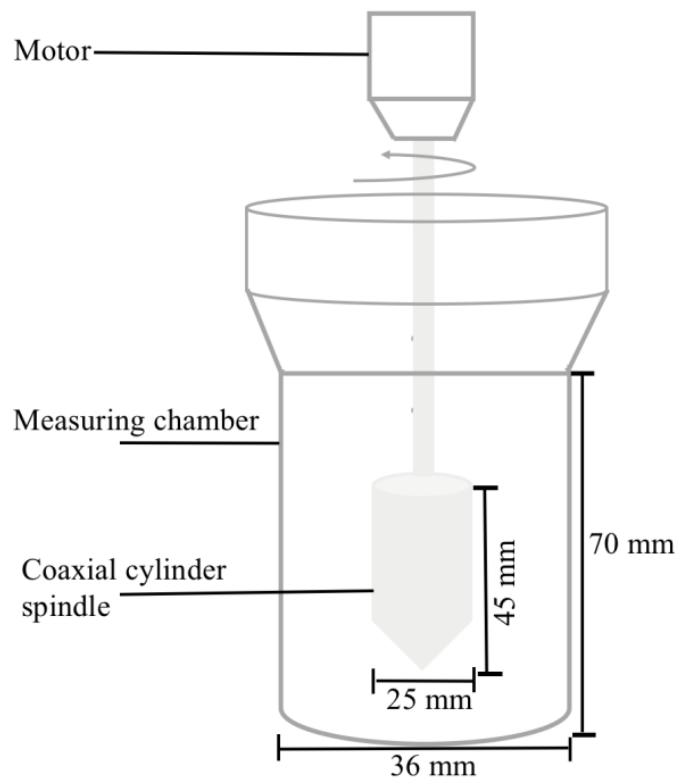

Figure 1: A simplified schematic representation showing the measuring chamber and coaxial cylinder spindle of a Brookfield rheometer for rheological properties measurements.

\section{Basic equations for rheology description}

Rheological properties of liquid and/or suspension foods have mostly been described using non-Newtonian fluid model equations such as the Power-law, Herschel-Bulkley, and Bingham models (Kokini 1992, Falguera and Ibarz 2010, Diamante and Umemoto 2015). The rheological properties vary between liquid foods, including juices depending on the components present and their structure interactions. As such, they often do not exhibit a direct proportionality between shear stress and shear rate (Ibarz et al. 1996, Falguera and Ibarz 2010, Diamante and Umemoto 2015). The experimental data of shear rate and shear stress acquired for samples were fitted by nonNewtonian fluid models: Power-law and Bingham model as shown in Equations (1) and 
(2). These model equations were applied to describe the flow behaviour of Aloe veramoringa leaf juice blends added with xanthan gum at different ratios.

The Power-law, also known as the Ostwald-de Waele model is shown in the Equation (1):

$$
\tau=K \gamma^{n}
$$

where $\tau(\mathrm{Pa})$ is the shear stress, $\gamma\left(\mathrm{s}^{-1}\right)$ is the shear rate, $K\left(\mathrm{~Pa} \mathrm{~s}^{\mathrm{n}}\right)$ is the consistency coefficient that serves as the viscosity index of the product, and $n$ (dimensionless) is the flow behaviour index. In Equation (1), the two rheological constants: $K$ and $n$ are very useful parameters for flow behaviour description. The model parameters were estimated by fitting the experimental data of shear stress, $\tau$ and shear rate, $\gamma$ to the Power-law Equation (1) for each juice sample.

When $n<1$, the product exhibits a shearthinning behaviour, which means the apparent viscosity decreases as the shear rate increases (Seyssiecq et al. 2003, Diamante and Umemoto 2015). Food products present shear-thickening properties when $n>1$, that means the apparent viscosity increases with the increase of shear rate. Newtonian behaviour is achieved as $n=1$ and no changes in viscosity with an increase of shear rate (Seyssiecq et al. 2003, Pevere et al. 2006, Keshani et al. 2012).

In the case of the Bingham model, the two model parameters, that is Bingham yield stress and plastic viscosity are pre-requisite parameters to describe a flow behaviour of the juice product (Björn et al. 2012, Keshani et al. 2012). The Bingham model is obtained by adding apparent yield stress to Newton's equation. Mathematically, it can be represented as in Equation (2):

$$
\tau=\tau_{0}+\eta \gamma
$$

where $\tau_{0}(\mathrm{~Pa})$ is the apparent yield stress, and $\eta$ $\left(\mathrm{Pa} \mathrm{s}^{\mathrm{n}}\right)$ is the plastic viscosity.

The flow behaviour of the product can be described, based on the magnitude of $\tau_{0}$, and $\eta$ parameters and at stresses above the apparent yield stress (Seyssiecq et al. 2003). The apparent yield stress is the minimum shear stress required to initiate product flow, and it depends on the product's internal structure and temperature (Boyd 2005).

The experimental data of shear stress, $\tau$ and shear rate, $\gamma$ for each juice sample were fitted to the Bingham model Equation (2). Thereafter, the Bingham model parameters were estimated using linear regression during which the intercept of $\tau$ and the slope give apparent yield stress, $\tau_{0}$ and plastic viscosity, $\eta$, respectively. When $\tau_{0}>1$, the juice sample exhibits a Bingham plastic behaviour and a Newtonian property when $\tau_{0}=0$.

\section{Results and Discussion \\ Flow behaviour}

Figure 2 shows flow behaviour for Aloe vera-moringa leaf juice blends: $\mathrm{S}_{1}$ to $\mathrm{S}_{6}$ in terms of shear stress and shear rate. The data for shear stress were acquired using a rheometer operating within a shear rate ranging from 500 to 3500 per sec. The $S_{1}$ sample had a much broader range of shear stress between 0 and 8.53 $\mathrm{Pa}$ when added with xanthan gum at different ratios. The other juice blends showed shear stresses ranging from 0 to $5.77,0.59$ to $3.66,0.28$ to $4.46,0.23$ to $2.88 \mathrm{~Pa}$, and from 0.26 to $5.35 \mathrm{~Pa}$ for $\mathrm{S}_{2}, \mathrm{~S}_{3}, \mathrm{~S}_{4}, \mathrm{~S}_{5}$, and $\mathrm{S}_{6}$, respectively when mixed with xanthan gum at different ratios. The control samples, i.e., those with no xanthan gum addition showed a narrow range of shear stress of approximately 0 and $0.55 \mathrm{~Pa}$. These rheograms indicate different flow behaviour of the Aloe vera-moringa leaf juice blends (Figure 2). For instance, the flow curves for all juice samples added with $0.4 \%$, $0.6 \%, 0.8 \%$, and $1 \%$ xanthan gum describe a non-Newtonian behaviour with different apparent yield stress. Besides, the apparent yield stress changes gradually with increasing in xanthan gum concentrations. This can plausibly be explained by the effect of xanthan gum addition to the Aloe vera-moringa juice blends, which forms a gel network structure as xanthan gum entraps sufficient water, thereby increasing the viscosity of the system (Somogyi 1996, Genovese and Lozano 2001, 
Liang et al. 2006). Moreover, the formation of the soluble complex may occur due to associative electrostatic interactions that related to steric stabilisation or bridging flocculation at the interfaces and control rheology properties (Genovese and Lozano 2001, Dickinson 2003, Mirhosseini et al. 2008, De Cássia da Fonseca et al. 2009, Ibrahim et al. 2011).

On the other hand, the control samples indicated a linear relationship between shear stress and shear rate that passes through the origin of coordinates (Figure 2). This suggests that the Aloe vera-moringa juices with no xanthan gum addition depict a Newtonian fluid behaviour. Also, a similar observation was found in all the juice blends $\left(S_{1}\right.$ to $\left.S_{6}\right)$ enriched with xanthan gum at $0.2 \%$ that exhibited a fairly Newtonian property as presented in Figure 2. This means the shear force employed was almost proportional to the shear rate produced. However, the data revealed a slight increase in shear stress with increasing shear rate. In other words, the Aloe vera-moringa leaf juice changes from a Newtonian fluid behaviour to non-Newtonian fluid behaviour as xanthan gum concentrations increase. Since, the Aloe vera-moringa leaf juice blends investigated exhibit different flow behaviour, therefore, further quantitative analysis is necessary to get more details on rheological properties.

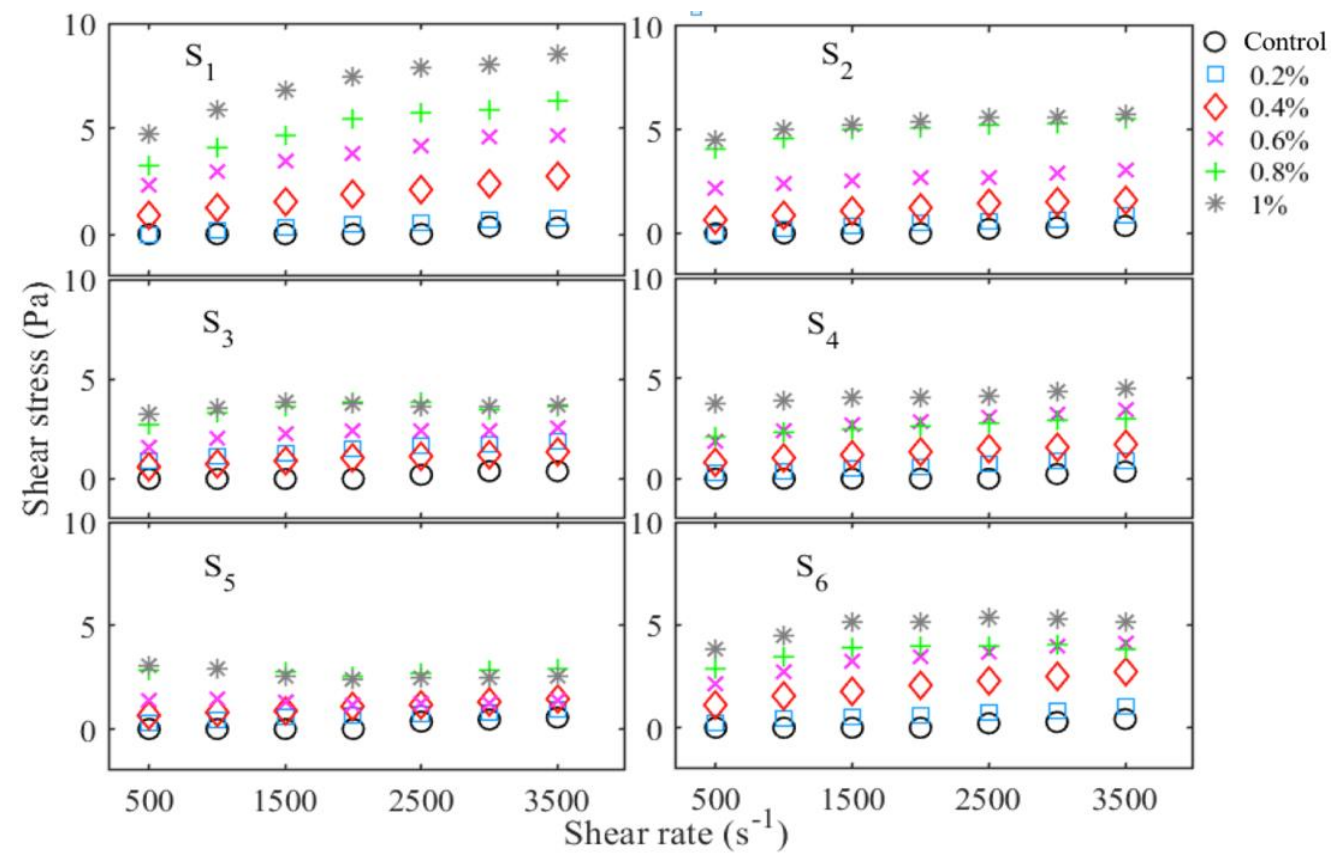

Figure 2: Rheograms illustrating the relationships between shear stress, $\tau(\mathrm{Pa})$ and shear rate, $\gamma$ $\left(\mathrm{s}^{-1}\right)$ for Aloe vera-moringa leaf juice blends: $S_{1}$ to $S_{6}$ each supplemented with xanthan gum at different ratios.

\section{Viscosity characterisation}

Figure 3 shows the relationship between apparent viscosity and shear rate for Aloe veramoringa leaf juice blends added with xanthan gum at different ratios. The results clearly show that an increase in xanthan gum concentrations significantly $(p<0.05)$ increased the viscosity in each sample of Aloe vera-moringa leaf juice blends (Figure 3). However, a decreasing trend in apparent viscosity was observed when the shear rate increased from 500 to 3500 per sec. Indeed, 
this was most noticeable in the juice samples enriched with high xanthan gum. At $1 \%$ xanthan gum, the juice samples presented significant $(p<0.05)$ changes in viscosity of about $74.1 \%\left(\mathrm{~S}_{1}\right), 79.6 \%\left(\mathrm{~S}_{2}\right), 81.8 \%\left(\mathrm{~S}_{3}\right)$, $88.2 \%\left(\mathrm{~S}_{4}\right), 82.9 \%\left(\mathrm{~S}_{5}\right)$, and $80.5 \%\left(\mathrm{~S}_{6}\right)$ as shown in Figure 3 . The viscosity profiles described a substantial reduction in viscosity at low shear rates, whereas at high shear rates, viscosity appeared to decrease slightly. The juice blends supplemented with xanthan gum at $0.4 \%$ to $1 \%$ describe the best rheological properties with non-Newtonian behaviour. These findings are consistent with the results of Gawai et al. (2017), who reported that the use of hydrocolloids at a concentration of less than $1 \%$ increases food consistency, improves the gelling property and control the texture and mouthfeel characteristics of products. Several other studies applied xanthan gum in different juices and found similar findings (Genovese and Lozano 2001, Beristain et al. 2006, Liang et al. 2006, Ibrahim et al. 2011, Udomsup et al. 2011). Genovese and Lozano (2001) and Ibrahim et al. (2011) studied the effect of hydrocolloids including xanthan gum on the quality and viscosity of apple juice and reported a reduction in viscosity with increasing shear rate. In mangosteen juice, Udomsup et al. (2011) showed that the addition of xanthan gum increases viscosity. Moreover, an increase in the xanthan gum concentrations significantly increased the viscosity of mangosteen juice. Similar results were also reported by Liang et al. (2006) in reconstituted carrot juice.

In contrast to a reduction in viscosity, the juice blends enriched with $0.2 \%$ xanthan gum and those of control samples indicated an insignificant change in viscosity as the shear rate increases from 500 to 3500 per sec (Figure 3 ). In this way, the viscosity profiles for control samples and juice samples enriched with $0.2 \%$ xanthan gum exemplify a Newtonian behaviour.

The rheological properties presented here prompted us to analyse our datasets using nonNewtonian model equations to obtain a comprehensive insight on the flow behaviour of Aloe vera-moringa juices. In doing so, these values of shear stress and shear rate were fitted to both Power-law and Bingham model equations as discussed in one of the sections.

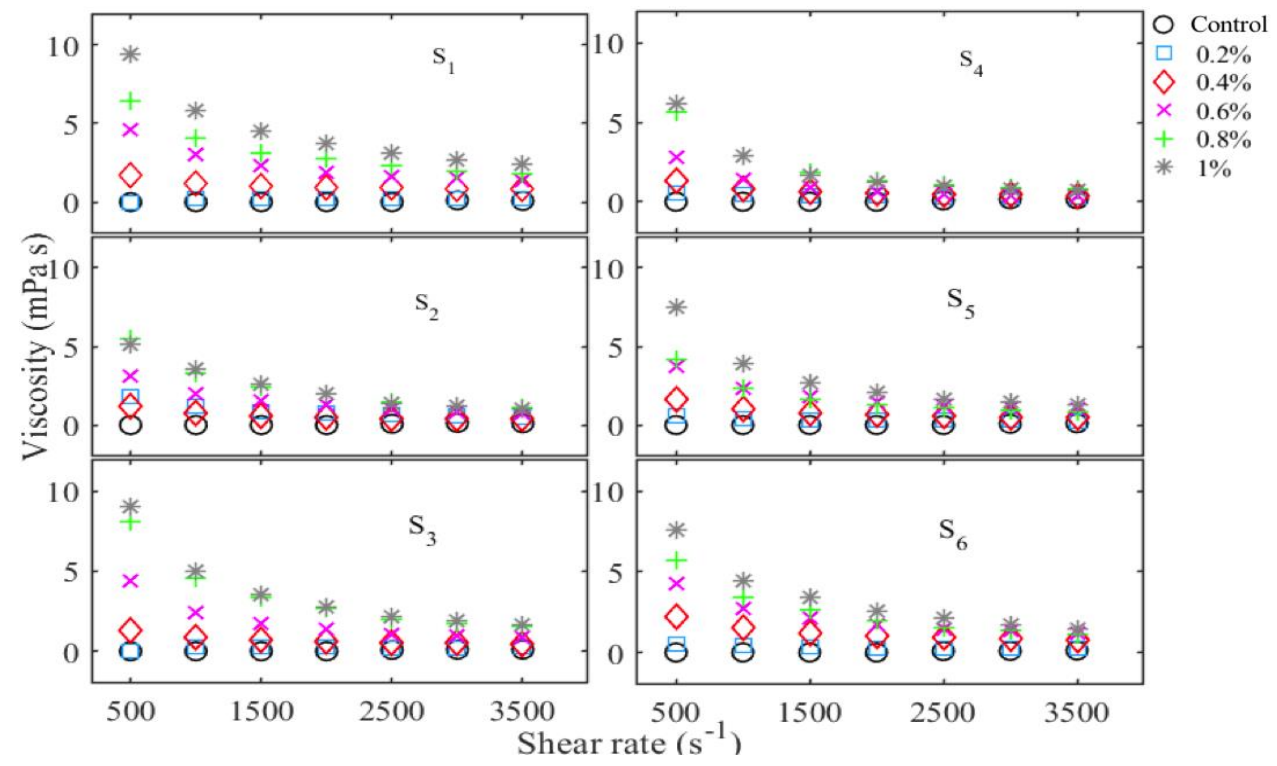

Figure 3: Experimental data for apparent viscosity measured from Aloe vera-moringa leaf juice blends: $S_{1}$ to $S_{6}$ each supplemented with xanthan gum at different ratios. 


\section{Model fitting}

Both Power-law and Bingham plastic model equations were applied to describe the flow behaviour information of Aloe veramoringa leaf juice blends. Table 2 shows the model parameter estimates, consistency coefficient, $K$ and flow behaviour index, $n$ achieved from the Power-law fitting of the experimental data of shear stress and shear rate. The model results show a shear-thinning behaviour with $n<1$ for all the juice samples enriched with xanthan gum at $0.4 \%$ to $1 \%$. The flow behaviour index, $n$ was in the range of 0.02 to 0.59 . In addition, the consistency coefficient (viscosity index), $K$ was observed to increase with increasing of xanthan gum concentrations in all the data fitted with the Power-law model (Equation 1). As such, the viscosity indices, $K$ ranged from 0.009 to 6.37 $\mathrm{Pa} \mathrm{s}^{\mathrm{n}}$ for all the juice blends supplemented with xanthan gum (Table 2). Several studies suggested that an increase in soluble solid contents has a strong, non-linear effect on the viscosity index, $K$ and the apparent viscosity of non-Newtonian foods (Krokida et al. 2001, Keshani et al. 2012, Diamante and Umemoto 2015). The power model fit was evaluated by analyses of the correlation coefficient, $R^{2}$ values. The results presented a good fitting to power law model with $R^{2}>0.98$ for most of the juice blends (Table 2 and Figure 4a-b). Again, all the control samples were found to be a Newtonian fluid property with a flow behaviour index, $n$ equal to 1 . This was also true for some juice blends supplemented with $0.2 \%$ xanthan gum.

In the case of the Bingham model (Equation 2), Table 3 presents the model parameter estimates that are apparent yield stress, $\tau_{0}$ and Bingham plastic viscosity, $\eta$ acquired after fitting the model to the experimental data of shear stress and shear rate. The general trend of increasing yield stress, $\tau_{0}$ with the increase in xanthan gum concentrations from 0.2 to $1 \%$ was observed in each Aloe vera-moringa juice blend. As such, apparent yield stress, increased from 0.08 to $4.63,0.81$ to $3.44,0.08$ to $4.56,0.23$ to 2.99 , 0.16 to 3.63 , and from 0.14 to $4.11 \mathrm{~Pa}$ for $\mathrm{S}_{1}$, $\mathrm{S}_{2}, \mathrm{~S}_{3}, \mathrm{~S}_{4}, \mathrm{~S}_{5}$, and $\mathrm{S}_{6}$, respectively, as shown in Table 3. The correlation coefficient, $R^{2}$ values for Bingham model fit were analysed and the results showed an adequate fitting with $R^{2}>$ 0.97 for the majority of the juice blends (Table 3 and Figure $4 c-d)$. However, the unsystematic trend of Bingham viscosity was observed in all the juice samples enriched with xanthan gum. These findings agree with the previous results of Diamante and Umemoto (2015) who reported a random pattern of Bingham viscosity in coriander puree, fenugreek puree, mint puree, and tamarind puree. For comparison purposes between the two models utilised in this study, the Power model showed a good fitting as highlighted in Figure 4.

The results presented in this work show the effects of xanthan gum on the rheological properties of Aloe vera-moringa leaf juice blends. In our opinion, such data are currently very scarce and of great interest in the rheological study area in the case of nutraceutical beverages like Aloe vera-moringa leaf juice blends. Furthermore, the rheological properties are used to evaluate the functional properties like flow behaviour, stability and quality, product performance, and consumer acceptance appraisal. The flow behaviour depends on process-structure-rheology relations. Several studies suggested that the addition of xanthan gum controls the rheological properties of the product through stabilisation and gelling effects (Somogyi 1996, Genovese and Lozano 2001, Dickinson 2003, Liang et al. 2006, Mirhosseini et al. 2008, Ibrahim et al. 2011, Udomsup et al. 2011). 
Tanz. J. Sci. Vol. 47(2), 2021
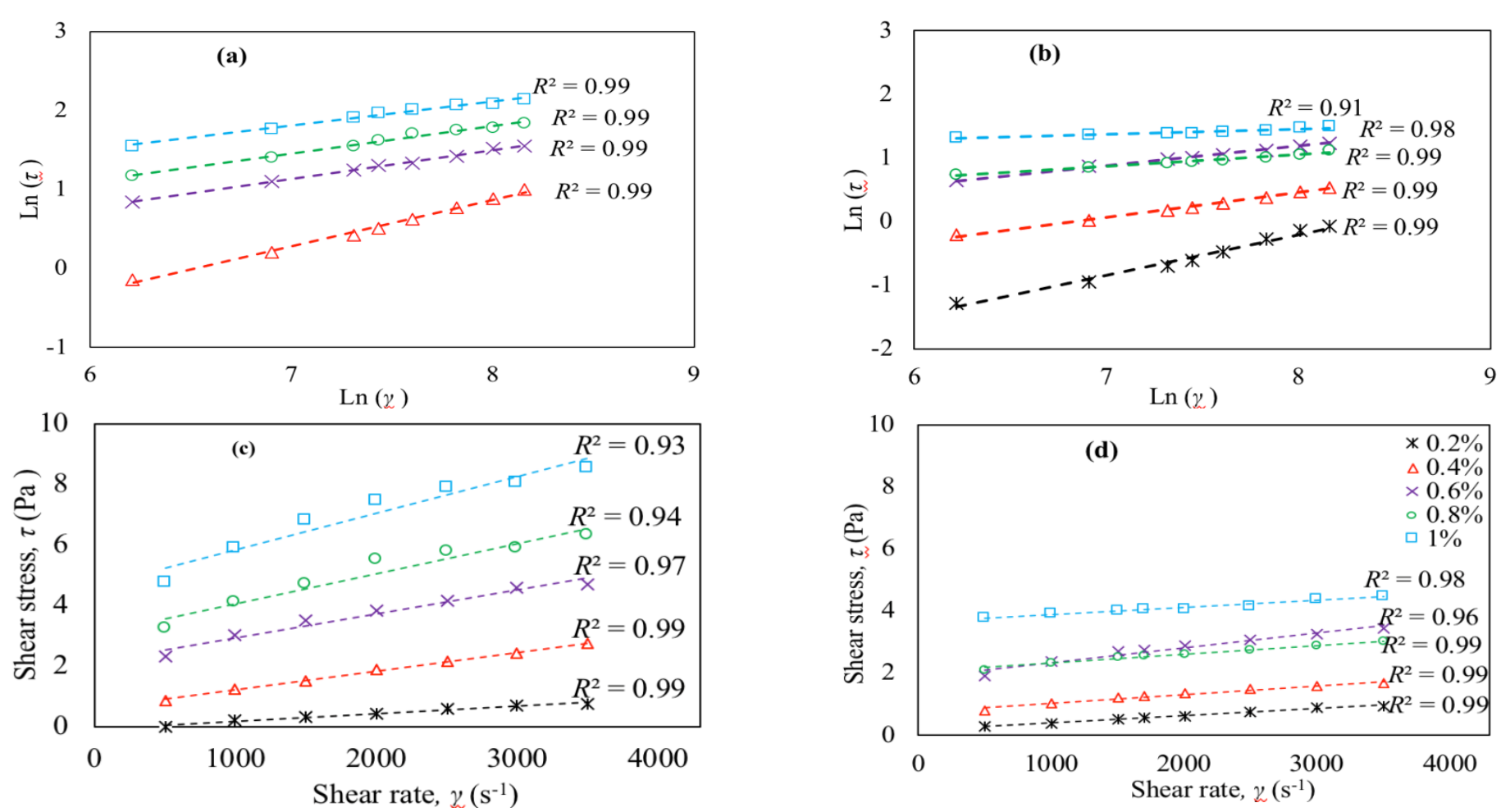

Figure 4: Model fittings for both the Power model (a-b) and the Bingham model (c-d) for the Aloe vera -moringa juice blends: $\mathrm{S}_{1}(\mathbf{a})$ and (c) and $S_{5}(\mathbf{b})$ and (d) supplemented with xanthan gum. The points are the experimental data and the dashed lines represent the model fit. outputs. 
Matabura and Rweyemamu - Effects of Xanthan gum on rheological properties of Aloe vera ...

Table 2: Power-law model parameters for each Aloe vera-moringa leaf juice formulations supplemented with xanthan gum at different ratios

\begin{tabular}{|c|c|c|c|c|}
\hline Sample & Xanthan gum (\%) & $\boldsymbol{K}\left(\mathrm{Pa} \mathrm{s}^{\mathrm{n}}\right)$ & $n$ & $R^{2}$ \\
\hline $\mathbf{S}_{1}$ & Control & & Newtonian & \\
\hline $\mathbf{S}_{1}$ & 0.2 & & Newtonian & \\
\hline $\mathbf{S}_{1}$ & 0.4 & 0.022 & 0.59 & 0.99 \\
\hline $\mathbf{S}_{1}$ & 0.6 & 0.234 & 0.37 & 0.99 \\
\hline $\mathbf{S}_{1}$ & 0.8 & 0.367 & 0.35 & 0.99 \\
\hline$S_{1}$ & 1.0 & 0.723 & 0.30 & 0.99 \\
\hline $\mathbf{S}_{2}$ & Control & & Newtonian & \\
\hline $\mathbf{S}_{2}$ & 0.2 & 0.085 & 0.38 & 0.99 \\
\hline $\mathbf{S}_{2}$ & 0.4 & 0.042 & 0.42 & 0.99 \\
\hline $\mathbf{S}_{2}$ & 0.6 & 0.402 & 0.24 & 0.95 \\
\hline $\mathbf{S}_{2}$ & 0.8 & 1.409 & 0.14 & 0.68 \\
\hline $\mathbf{S}_{2}$ & 1.0 & 2.650 & 0.05 & 0.48 \\
\hline $\mathbf{S}_{3}$ & Control & & Newtonian & \\
\hline $\mathbf{S}_{3}$ & 0.2 & & Newtonian & \\
\hline $\mathbf{S}_{3}$ & 0.4 & 0.040 & 0.45 & 0.99 \\
\hline $\mathbf{S}_{\mathbf{3}}$ & 0.6 & 0.830 & 0.16 & 0.97 \\
\hline $\mathbf{S}_{\mathbf{3}}$ & 0.8 & 1.609 & 0.15 & 0.98 \\
\hline $\mathbf{S}_{3}$ & 1.0 & 2.194 & 0.12 & 0.99 \\
\hline $\mathbf{S}_{4}$ & Control & & Newtonian & \\
\hline $\mathbf{S}_{4}$ & 0.2 & 0.009 & 0.57 & 0.99 \\
\hline $\mathbf{S}_{4}$ & 0.4 & 0.052 & 0.40 & 0.98 \\
\hline $\mathbf{S}_{4}$ & 0.6 & 2.050 & 0.06 & 0.93 \\
\hline $\mathbf{S}_{4}$ & 0.8 & 3.144 & 0.02 & 0.96 \\
\hline $\mathbf{S}_{4}$ & 1.0 & 6.370 & 0.12 & 0.81 \\
\hline $\mathbf{S}_{5}$ & Control & & Newtonian & \\
\hline $\mathbf{S}_{5}$ & 0.2 & 0.005 & 0.64 & 0.99 \\
\hline $\mathbf{S}_{5}$ & 0.4 & 0.073 & 0.38 & 0.99 \\
\hline $\mathbf{S}_{5}$ & 0.6 & 0.293 & 0.30 & 0.99 \\
\hline $\mathbf{S}_{5}$ & 0.8 & 0.673 & 0.18 & 0.98 \\
\hline$S_{5}$ & 1.0 & 2.161 & 0.09 & 0.97 \\
\hline$S_{6}$ & Control & & Newtonian & \\
\hline$S_{6}$ & 0.2 & 0.004 & 0.67 & 0.98 \\
\hline$S_{6}$ & 0.4 & 0.066 & 0.45 & 0.99 \\
\hline$S_{6}$ & 0.6 & 0.265 & 0.34 & 0.99 \\
\hline$S_{6}$ & 0.8 & 1.140 & 0.16 & 0.81 \\
\hline$S_{6}$ & 1.0 & 1.378 & 0.17 & 0.85 \\
\hline
\end{tabular}


Tanz. J. Sci. Vol. 47(2), 2021

Table 3: Bingham plastic model parameters for each Aloe vera-moringa leaf juice formulations supplemented with xanthan gum at different ratios.

\begin{tabular}{|c|c|c|c|c|}
\hline Sample & Xanthan gum (\%) & $\tau_{0}(\mathrm{~Pa})$ & $\eta\left(\mathrm{mPa} \mathrm{s}^{\mathrm{n}}\right)$ & $R^{2}$ \\
\hline \multicolumn{5}{|c|}{ Control } \\
\hline $\mathbf{S}_{1}$ & 0.2 & 0.08 & 0.20 & 0.99 \\
\hline $\mathbf{S}_{1}$ & 0.4 & 0.60 & 0.60 & 0.99 \\
\hline $\mathbf{S}_{1}$ & 0.6 & 2.14 & 0.80 & 0.97 \\
\hline $\mathbf{S}_{1}$ & 0.8 & 3.07 & 1.00 & 0.94 \\
\hline$S_{1}$ & 1.0 & 4.63 & 1.20 & 0.93 \\
\hline $\mathbf{S}_{2}$ & Control & & & \\
\hline $\mathbf{S}_{2}$ & 0.2 & 0.81 & 0.30 & 0.98 \\
\hline $\mathbf{S}_{2}$ & 0.4 & 0.51 & 0.20 & 0.99 \\
\hline $\mathbf{S}_{\mathbf{2}}$ & 0.6 & 1.66 & 0.30 & 0.83 \\
\hline $\mathbf{S}_{\mathbf{2}}$ & 0.8 & 3.02 & 0.20 & 0.41 \\
\hline $\mathbf{S}_{2}$ & 1.0 & 3.44 & 0.08 & 0.23 \\
\hline $\mathbf{S}_{3}$ & Control & & & \\
\hline $\mathbf{S}_{3}$ & 0.2 & 0.08 & 0.30 & 0.97 \\
\hline $\mathbf{S}_{\mathbf{3}}$ & 0.4 & 0.60 & 0.30 & 0.97 \\
\hline $\mathbf{S}_{\mathbf{3}}$ & 0.6 & 2.13 & 0.20 & 0.98 \\
\hline $\mathbf{S}_{3}$ & 0.8 & 4.10 & 0.40 & 0.88 \\
\hline $\mathbf{S}_{3}$ & 1.0 & 4.56 & 0.40 & 0.91 \\
\hline $\mathbf{S}_{\mathbf{4}}$ & Control & & & \\
\hline $\mathbf{S}_{4}$ & 0.2 & 0.23 & 0.20 & 0.99 \\
\hline $\mathbf{S}_{4}$ & 0.4 & 0.54 & 0.30 & 0.99 \\
\hline $\mathbf{S}_{4}$ & 0.6 & 1.38 & 0.04 & 0.90 \\
\hline $\mathbf{S}_{4}$ & 0.8 & 2.78 & 0.01 & 0.92 \\
\hline $\mathbf{S}_{4}$ & 1.0 & 2.99 & 0.20 & 0.99 \\
\hline $\mathbf{S}_{5}$ & Control & & & \\
\hline$S_{5}$ & 0.2 & 0.16 & 0.20 & 0.99 \\
\hline $\mathbf{S}_{5}$ & 0.4 & 0.72 & 0.30 & 0.99 \\
\hline $\mathbf{S}_{5}$ & 0.6 & 1.84 & 0.50 & 0.96 \\
\hline $\mathbf{S}_{5}$ & 0.8 & 2.02 & 0.30 & 0.99 \\
\hline $\mathbf{S}_{5}$ & 1.0 & 3.63 & 0.20 & 0.98 \\
\hline$S_{6}$ & Control & & & \\
\hline $\mathbf{S}_{6}$ & 0.2 & 0.14 & 0.20 & 0.98 \\
\hline$S_{6}$ & 0.4 & 0.97 & 0.50 & 0.99 \\
\hline$S_{6}$ & 0.6 & 2.12 & 0.60 & 0.92 \\
\hline $\mathbf{S}_{6}$ & 0.8 & 3.19 & 0.30 & 0.53 \\
\hline$S_{6}$ & 1.0 & 4.11 & 0.40 & 0.60 \\
\hline
\end{tabular}

\section{Conclusion}

The results presented in this work demonstrated that addition of xanthan gum to the Aloe vera-moringa leaf juice blend significantly changes viscosity, shear stress, and flow behaviour. In this respect, the rheological results unveil a reduction trend in viscosity as shear rate increases, except for the control samples and juice blends $S_{1}$ and $S_{3}$ when supplemented with $0.2 \%$ xanthan gum. 
The Aloe vera-moringa leaf juice was observed to change from a Newtonian fluid behaviour to non-Newtonian fluid behaviour when the xanthan gum concentrations increase. Moreover, shear stress increases with increasing xanthan gum concentrations. This implies that the uses of xanthan gum affect flow behaviour of Aloe vera-moringa juice, which is the most important functional properties in nutraceutical beverage processing and storability. The rheological properties of Aloe vera-moringa leaf juice were described well with both Power-law and Bingham plastic models. The rheology properties of Aloe veramoringa leaf juice blends were described well with the Power-law model. The juice blends supplemented with xanthan gum of $0.4 \%$ to $1 \%$ found to depict a shear-thinning behaviour with flow behaviour index, $n<1$. To the best of our knowledge, the findings presented in this study are novel and can be useful in describing the rheological properties of nutraceutical beverages. Besides, future investigations will be devoted to studying the physicochemical properties, nutraceutical compositions and organoleptic evaluation of Aloe vera-moringa juice during storage to assess therapeutic potential, consumer's acceptability and effectiveness of the functional beverage to improve human health.

\section{Acknowledgment}

The authors wish to acknowledge the botanical garden of the Mlimani Campus University of Dar es Salaam and Stayfit Nutrisupplies Company Limited for providing Aloe vera and moringa leaves. This research work received no special research funds.

Declaration of competing interest: The authors declare that they have no competing interests to disclose.

Availability of data and materials: The full datasets generated and used by this study are available from the authors upon reasonable request.

\section{References}

Aja PM, Nwachukwu N, Ibiam UA, Igwenyi IO, Offor CE and Orji UO 2014 Chemical constituents of Moringa oleifera leaves and seeds from Abakaliki, Nigeria. Am. J. Phytoed. Clin. Ther. 2(3): 310-321.

Alphonce S, Kaale LD, Rweyemamu LM and Millinga F 2019 Proximate composition of fermented cassava meal "mchuchume" fortified with soya bean flour and Moringa oleifera leaves powder. J. Food Sci. Technol. 56(8): 3660-3667.

Beristain CI, Cruz-Sosa F, Lobato-Calleros C, Pedroza-Islas R, Rodríguez-Huezo ME and Verde-Calvo JR 2006 Applications of soluble dietary fibers in beverages. Rev. Mex. Ing. 5(1): 81-95.

Biswas S, Masih D, Singh M and Sonkar C 2016 Development and quality evaluation of Aloe Vera and pineapple juice blended beverage. Int. Res. J. Eng. Technol. 3: 214219.

Boniface J, Kaale L, Msita H and Rweyemamu L 2020 Effects of onion juice and Moringa oleifera leaf juice on the shelf life of sugarcane juice. Tanz. J. Sci. 46(2): 573584.

Boyd M 2005 The phase behaviour of xanthan based biopolymer mixtures. $\mathrm{PhD}$ thesis, University of Nottingham.

Björn A, de La Monja PS, Karlsson A, Ejlertsson J and Svensson BH 2012 Rheological characterization. Biogas 1: 6376.

Chhikara N, Kaur A, Mann S, Garg MK, Sofi SA and Panghal A 2020 Bioactive compounds, associated health benefits and safety considerations of Moringa oleifera L.: an updated review. Nutr. Food Sci. 51(2): 255-277.

De Cássia da Fonseca V, Haminiuk CWI, Izydoro DR, Waszczynskyj N, de Paula Scheer A and Sierakowski MR 2009 Stability and rheological behaviour of salad dressing obtained with whey and different combinations of stabilizers. Int. J. Food Sci. Technol. 44(4): 777-783. 
Diamante L and Umemoto M 2015 Rheological properties of fruits and vegetables: a review. Int. J. Food Prop. 18(6): 1191-1210.

Dickinson E 2003 Hydrocolloids at interfaces and the influence on the properties of dispersed systems. Food Hydrocoll. 17(1): 25-39.

Đorđević V, Balanč B, Belščak-Cvitanović A, Lević S, Trifković K, Kalušević A, Kostić I, Komes D, Bugarski B and Nedović V 2015 Trends in encapsulation technologies for delivery of food bioactive compounds. Food Eng. Rev. 7(4): 452-490.

Doyon M and Labrecque J 2008 Functional foods: a conceptual definition. Br. Food J. $110,1133-1149$.

Falguera V and Ibarz A 2010 A new model to describe flow behaviour of concentrated orange juice. Food Biophys. 5(2): 114-119.

Fahey JW 2005 Moringa oleifera: a review of the medical evidence for its nutritional, therapeutic, and prophylactic properties. Part 1. Tree. Life J. 1(5): 1-15.

Gawai KM, Mudgal SP and Prajapati JB 2017 Stabilizers, colorants, and exopolysaccharides in yogurt. In: Shah NP (Ed) Yogurt in Health and Disease Prevention (pp. 49-68). Academic Press.

Genovese DB and Lozano JE 2001 The effect of hydrocolloids on the stability and viscosity of cloudy apple juices. Food Hydrocoll. 15(1): 1-7.

Goncharov N, Orekhov AN, Voitenko N, Ukolov A, Jenkins R and Avdonin P 2016 Nutraceuticals: Efficacy, Safety and Toxicity. In: Gupta RC (Ed). Academic Press, 177.

Hęś M, Dziedzic K, Górecka D, JędrusekGolińska A and Gujska E 2019 Aloe vera (L.) Webb.: natural sources of antioxidants-a review. Plant Foods Hum. Nutr. 74(3), 255-265.

Ibarz A, Garvin A and Costa J 1996 Rheological behaviour of sloe (Prunus spinosa) fruit juices. J. Food Eng. 27(4): 423-430.
Ibrahim GE, Hassan IM, Abd-Elrashid AM, ElMassry KF, Eh-Ghorab AH, Manal MR and Osman F 2011 Effect of clouding agents on the quality of apple juice during storage. Food Hydrocoll. 25(1): 91-97.

Joy K and Rani RNA 2013 Formulation, sensory evaluation and nutrient analysis of products with Aloe vera. World J. Pharm. Pharmac. Sci. 2(6): 5321-5328.

Katalenić M 2013 Essential guide to food additives. Food Technol. Biotechnol. 51(2): 309-312.

Keshani S, Chuah AL and Russly AR 2012 Effect of temperature and concentration on rheological properties pomelo juice concentrates. Int. Food Res. J. 19(2): 553362.

Kokini JL 1992 Rheological Properties of Food. In: Heldman DR and Lund DB (Eds) Handbook of Food Engineering (pp.17-38), Marcel Dekker: New York.

Krokida MK, Maroulis ZB and Saravacos GD 2001 Rheological properties of fluid fruit and vegetable puree products: compilation of literature data. Int. J. Food Prop. 4(2): 179-200.

Kumar KS and Debjit B 2010 Aloe vera: a potential herb and its medicinal importance. J. Chem. Pharm. Res. 2(1): 21-29.

Liang C, Hu X, Ni Y, Wu J, Chen F and Liao X 2006 Effect of hydrocolloids on pulp sediment, white sediment, turbidity and viscosity of reconstituted carrot juice. Food Hydrocoll. 20(8): 1190-1197.

Matabura VV and Kibazohi O 2021 Physicochemical and sensory evaluation of mixed juices from banana, pineapple and passion fruits during storage. Tanz. J. Sci. 47(1): 332-343.

Mirhosseini H, Tan CP, Aghlara A, Hamid NS, Yusof S and Chern BH 2008 Influence of pectin and CMC on physical stability, turbidity loss rate, cloudiness and flavour release of orange beverage emulsion during storage. Carbohydr. Polym. 73(1): 83-91.

Pevere A, Guibaud G, Van Hullebusch E, Lens $\mathrm{P}$ and Baudu M 2006 Viscosity evolution of 
Matabura and Rweyemamu - Effects of Xanthan gum on rheological properties of Aloe vera ...

anaerobic granular sludge. Biochem. Eng. J. 27(3): 315-322.

Rahman M, Markad ML, Kulkarni TS and Meghdambar PV 2015 Sensory attributes of the mixed fruit jam made from aloe vera, pineapple and mango. Int. J. Sci. Res. 4(10): 408-412.

Rweyemamu LM, Yusuph A and Mrema GD 2015 Physical properties of extruded snacks enriched with soybean and moringa leaf powder. Afr. J. Food Sci. Technol. 6: 28-34.

Sahu PK, Giri DD, Singh R, Pandey P, Gupta S, Shrivastava AK, Kumar A and Pandey KD 2013 Therapeutic and medicinal uses of Aloe vera: a review. Pharmacol. Pharm. 4(8): 599-610.

Santos DI, Saraiva JMA, Vicente AA and Moldão-Martins M 2019 Methods for determining bioavailability and bioaccessibility of bioactive compounds and nutrients. In: Barba, FJ, Saraiva JMA, Cravotto $\mathrm{G}$ and Lorenzo JM (Eds) Innovative thermal and non-thermal processing, bioaccessibility and bioavailability of nutrients and bioactive compounds (pp. 23-54), Woodhead Publishing.

Sauer S and Plauth A 2017 Health-beneficial nutraceuticals - myth or reality?. Appl. Microbiol. Biotechnol. 101(3): 951-961.
Seyssiecq I, Ferrasse JH and Roche N 2003 State-of-the-art: rheological characterisation of wastewater treatment sludge. Biochem. Eng. J. 16(1): 41-56.

Shahidi F 2012 Nutraceuticals, functional foods and dietary supplements in health and disease. J. Food Drug Anal. 20(1): 226230.

Somogyi LP 1996 Direct food additives in fruit processing. In: Somogyi LP, Ramaswamy HS and Hui YH (Eds) Processing Fruits Science and Technology (pp. 293-361), Publ. Co. Inc., Lancaster, Basel.

Sunita M and Ananya S 2013 To study the physico-chemical properties of bael and Aloe vera blended beverages. Int. J. Sci. Res. 4(9): 642-645.

Udomsup $\mathrm{T}$, Therdthai $\mathrm{N}$ and Harnsilawat $\mathrm{T}$ 2011 Effect of xanthan gum and carboxymethyl cellulose concentration on quality of cloudy mangosteen juice. In: Proceedings of the Kesetsart University Annual Conference, Thailand, 1-4 February 2011 (pp.43-50).

Vergara-Jimenez M, Almatrafi MM and Fernandez ML 2017 Bioactive components in Moringa oleifera leaves protect against chronic disease. Antioxidants 6(4): 91. 